Article

\title{
A Sensitive, Point-of-Care Detection of Small Molecules Based on a Portable Barometer: Aflatoxins In Agricultural Products
}

\author{
Weiqi Zhang ${ }^{1, \dagger}$, Wenqin Wu ${ }^{1, \dagger}$, Chong Cai ${ }^{1}$, Xiaofeng $\mathrm{Hu}^{1,2,3}$, Hui Li ${ }^{1,2,3,4,5}$, Yizhen Bai ${ }^{1}$, \\ Zhaowei Zhang $1,2,3,4,5, *$ (i) and Peiwu Li ${ }^{1,2,3,5}$ \\ 1 Oil Crops Research Institute of the Chinese Academy of Agricultural Sciences, Wuhan 430062, China; \\ 82101175194@caas.cn (W.Z.); wuwenqin02@gmail.com (W.W.); 82101185206@caas.cn (C.C.); \\ huxiaofeng@caas.cn (X.H.); lihui04@caas.cn (H.L.); baiyizhen@caas.cn (Y.B.); peiwuli@oilcrops.cn (P.L.) \\ Key Laboratory of Detection for Mycotoxins, Ministry of Agriculture, Wuhan 430062, China \\ National Reference Laboratory for Agricultural Testing (Biotoxin), Wuhan 430062, China \\ 4 Key Laboratory of Biology and Genetic Improvement of Oil Crops, Ministry of Agriculture, \\ Wuhan 430062, China \\ 5 Laboratory of Risk Assessment for Oilseeds Products, Wuhan, Ministry of Agriculture, Wuhan 430062, China \\ * Correspondence: zwzhang@whu.edu.cn; Tel.: +86-27-8671-1839 \\ + These authors contribute equally to this work.
}

Received: 7 February 2020; Accepted: 1 March 2020; Published: 3 March 2020

\begin{abstract}
Sensitive and point-of-care detection of small toxic molecules plays a key role in food safety. Aflatoxin, a typical small toxic molecule, can cause serious healthcare and economic issues, thereby promoting the development of sensitive and point-of-care detection. Although ELISA is one of the official detection methods, it cannot fill the gap between sensitivity and point-of-care application because it requires a large-scale microplate reader. To employ portable readers in food safety, Pt-catalysis has attracted increasing attention due to its portability and reliability. In this study, we developed a sensitive point-of-care aflatoxin detection (POCAD) method via a portable handheld barometer. We synthesized and characterized Au@PtNPs and Au@PtNPs conjugated with a second antibody (Au@PtNPs-IgG). A competitive immunoassay was established based on the homemade monoclonal antibody against aflatoxins. Au@PtNPs-IgG was used to catalyze the production of $\mathrm{O}_{2}$ from $\mathrm{H}_{2} \mathrm{O}_{2}$ in a sealed vessel. The pressure of $\mathrm{O}_{2}$ was then recorded by a handheld barometer. The aflatoxin concentration was inversely proportional to the pressure recorded via the barometer reading. After optimization, a limit of detection of $0.03 \mathrm{ng} / \mathrm{mL}$ and a linear range from 0.09 to $16.0 \mathrm{ng} / \mathrm{mL}$ were achieved. Recovery was recorded as $83.1 \%-112.0 \%$ along with satisfactory results regarding innerand inter-assay precision (relative standard deviation, RSD $<6.4 \%$ ). Little cross-reaction was observed. Additionally, the POCAD was validated by high-performance liquid chromatography (HPLC) by using peanut and corn samples. The portable POCAD exhibits strong potential for applications in the on-site detection of small toxic molecules to ensure food safety.
\end{abstract}

Keywords: aflatoxin; mycotoxin; Au@PtNPs; immunoassay; handheld barometer

Key Contribution: In this paper, using gold core platinum cell nanoparticles and a portable barometer, a new competitive-type pressure-dependent immunoassay method to detect aflatoxin was developed, well-optimized and evaluated. 


\section{Introduction}

Aflatoxins are mainly synthetized from a polyketide pathway of Aspergillus flavus and Aspergillus parasiticus [1]. Aflatoxins have been considered as the major food safety threat since their initial detection in the 1960s [2]. The toxicity of aflatoxin is essentially due to: (i) acute aflatoxicosis resulting in hepatic damage, alimentary tract harm, and even death [3]; and (ii) chronic exposure resulting in mutagenic and hepatotoxic effects, immune suppression, and cancer [4]. It was also reported that aflatoxins induce $4.6 \%-28.2 \%$ of global hepatocellular carcinoma [5]. The major agricultural products and food matrices are easily contaminated by aflatoxins from farm to table under favorable environmental conditions, especially in peanut and corn [6]. Serious aflatoxin-induced food safety issues cause billions of dollars to be lost in trading and health care. Currently, many strict regulations of aflatoxin have been set by most regions, such as GB 2761-2017 of China, with the level ranging from 2 to $20 \mathrm{ng} / \mathrm{mL}[7,8]$. Thus, monitoring aflatoxin contamination in agro-food is essential, due to a growing demand for on-site aflatoxin monitoring.

The typical analytical methods for aflatoxin detection are high-performance liquid chromatography (HPLC) and high-performance liquid chromatography-tandem mass spectrometry (HPLC-MS/MS) $[8,9]$. These approaches offer excellent sensitivity and stability and are high-throughput. Because these methods require extensive time and labor, expensive instruments, and skilled technicians, they cannot satisfy the need for point-of-care aflatoxin detection (POCAD). Enzyme-linked immunosorbent assay (ELISA) boasts the merits of high sensitivity and specificity and easy operation [10]. However, the requirement for a microplate reader has hampered the wide application of ELISA as an on-site detection method.

One serial of point-of-care detection method has been developed by using different signal-amplifying nanomaterials as substitutes for horseradish peroxidase (HRP), such as the introduction of the emerging platinum nanoparticles (PtNPs) [11-13]. The catalytic efficiency of PtNPs has been shown to be 400 times higher than that of catalase [14]. Due to the high cost and low availability of PtNPs, monometallic catalysts are substituted by bimetallic or multimetal catalysts $[15,16]$. Gold nanoparticles (AuNPs) are useful nanostructures due to their great biocompatibility, stability, and optical and electronic properties [15]. The Au@PtNPs, gold core platinum cell nanoparticles, were effectively introduced in catalysis [17], immunochromatographic strips [18], and bar-chart chips [19,20]. To the best of our knowledge, there are few reports on the use of $\mathrm{Pt}$ in the detection of small molecules in the context of food safety.

In this paper, we synthesized Au@PtNPs-IgG (connection of Au@PtNPs and goat anti-mouse antibody) as a signal amplifier and then established a sensitive method for point-of-care detection of small molecules based on a handheld barometer with aflatoxins in agro-food as an example. Under optimal parameters, we evaluated the limit of detection (LOD), linear range, and average recovery. This POCAD was further validated by high-performance liquid chromatography (HPLC) using spiked peanut and corn samples. This POCAD can be widely applied in food safety and environmental monitoring.

\section{Results and Discussion}

\subsection{Principle of POCAD}

As reported in Figure 1, the entire POCAD was conducted in a sealed microwell. First, the aflatoxin $\mathrm{B}_{1}\left(\mathrm{AFB}_{1}\right)$ antigen was coated on the bottom of the microwell before the extracting sample solution and monoclonal antibody $(\mathrm{mAb})$ against aflatoxins were simultaneously added. After washing steps, the Au@PtNP-IgG was added into the microwell. Later, the rapid addition of $\mathrm{H}_{2} \mathrm{O}_{2}$ produced $\mathrm{O}_{2}$ in the sealed microwell. The pressure in the microwell is in inverse proportion to the aflatoxin concentration. By using the handheld barometer, we recorded the pressure in the microwell and calculated the aflatoxin concentration via the external standard method. 


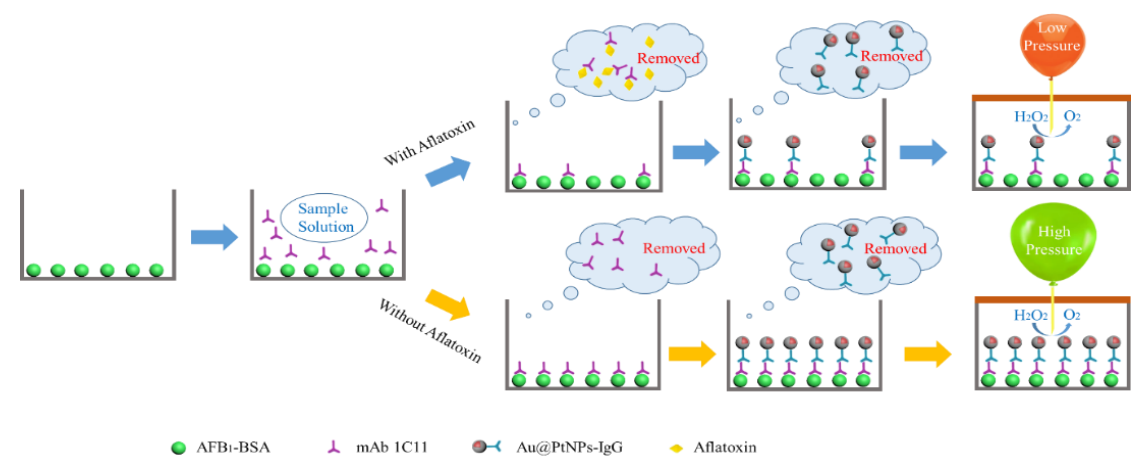

Figure 1. Scheme of point-of-care aflatoxin detection (POCAD) of aflatoxins. The entire POCAD was conducted in a sealed microwell. The $\mathrm{AFB}_{1}$ antigen was coated on the bottom of the microwell. During the immunoassay, the aflatoxin and antigen compete with the binding site of the mAb. After adding of Au@PtNP-IgG, Au@PtNP-IgG bind with mAb connected to the antigen. Later, the rapid addition of $\mathrm{H}_{2} \mathrm{O}_{2}$ produced $\mathrm{O}_{2}$ in the sealed microwell. The pressure in the microwell is in inverse proportion to the aflatoxin concentration. By using the handheld barometer, we recorded the pressure in the microwell and calculated the aflatoxin concentration via the external standard method.

\subsection{Characterization of Au@PtNPs}

We employed X-ray diffraction (XRD), UV-vis, high-resolution transmission electron microscopy (HRTEM), and selected area electron diffraction (SAED) for Au@PtNP characterization. In Figure 2A, XRD peaks at $81.82^{\circ}, 77.48^{\circ}, 64.62^{\circ}, 44.44^{\circ}$, and $38.32^{\circ}$ correspond to (222), (311), (220), (200), and (111) planes of $\mathrm{Au}$ (JCPDS-04-0784) [21]. The other peaks at $85.70^{\circ}, 81.06^{\circ}, 67.43^{\circ}, 46.30^{\circ}$, and $37.76^{\circ}$ were in agreement with (222), (311), (220), (200), and (111) planes of Pt (JCPDS-04-0802) [22]. These XRD results demonstrated the successful fabrication of the Au@PtNPs. The Au@PtNPs were characterized using UV-vis spectroscopy (Figure 2B). Compared with the Au peak, the Au@PtNP peak was slightly blueshifted from $521 \mathrm{~nm}$ to $517 \mathrm{~nm}$, corresponding to previous work [23]. The HRTEM pattern indicated that the Au@PtNPs (Figure 3A) was homogenous. Comparing with the HRTEM pattern of AuNPs (Figure 3B), we found an increasing diameter from 13 to $16 \mathrm{~nm}$ for Au@PtNPs. This finding suggested that a thin layer of Pt was successfully deposited on the AuNPs surface. In addition, the SAED pattern of Au@PtNPs (Figure 3C) exhibited the intense spot of Pt shells in a ring pattern, which matched well with (222), (311), (220), (200), and (111) planes. The SAED results indicated that the crystalline structure of Au@PtNPs was the face-centered-cubic (fcc) crystal structure, which was in good agreement with the XRD result.

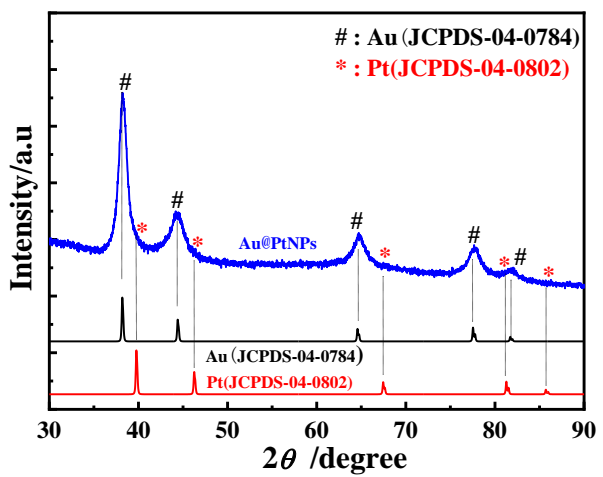

(A)

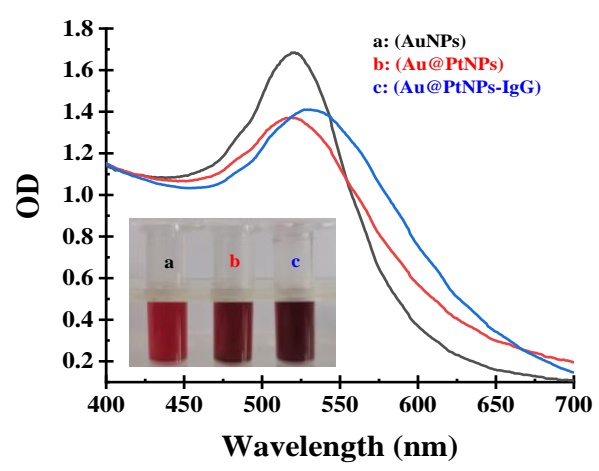

(B)

Figure 2. (A) X-ray diffraction pattern of Au@PtNPs (black line: Au (JCPDS-04-0784) standard PDF card, red line: Pt (JCPDS-04-0802) standard PDF card, blue line: the diffraction pattern of Au @ PtNPs); (B) exhibits UV-visible spectroscopy of AuNPs (a), Au@PtNPs (b), and Au@PtNPs-IgG (c). 

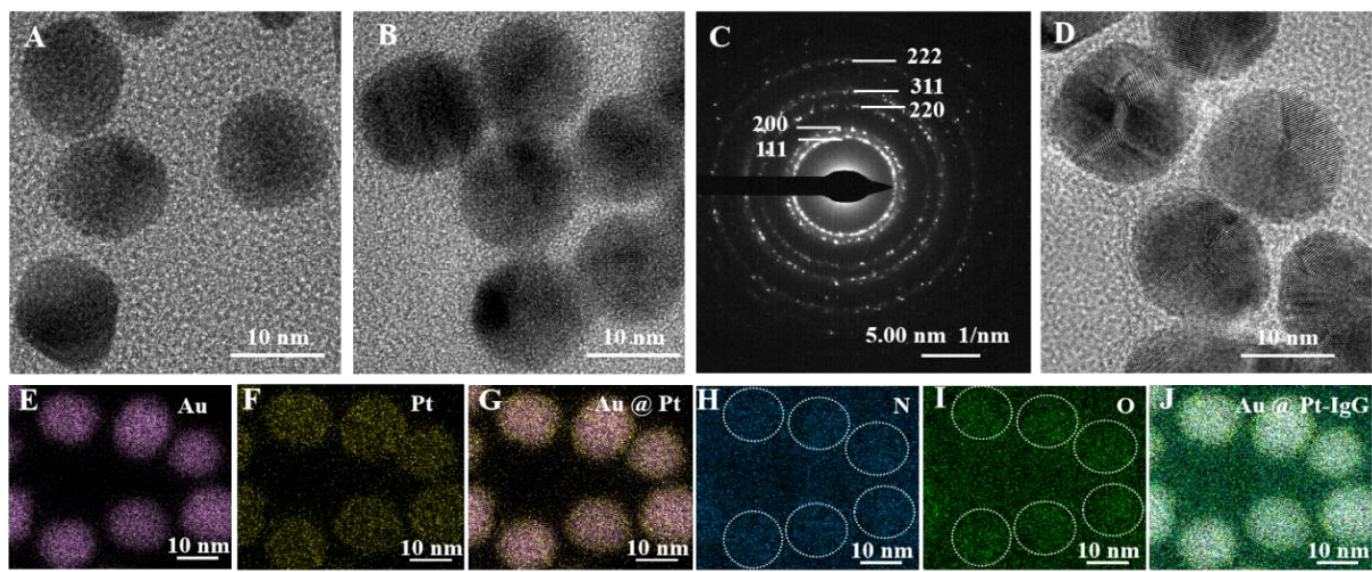

Figure 3. High-resolution transmission electron microscopy (HRTEM) images of Au (A), Au@PtNPs (B), and Au@PtNPs-IgG (D); selected area electron diffraction (SAED) of Au@PtNPs (C); and elemental mappings of $\mathrm{Au}(\mathbf{E}), \mathrm{Pt}(\mathbf{F}), \mathrm{Au} @ P t N P s(G), \mathrm{N}(\mathbf{H}), \mathrm{O}(\mathbf{I})$, and all elements (J) in Au@PtNPs-IgG. Scale bar: $10 \mathrm{~nm}$.

\subsection{Synthesis of Au@PtNPs-IgG}

In the synthesis of Au@PtNPs-IgG, we optimized the $\mathrm{pH}$ value, blocking buffer and IgG consumption to achieve the optimal POCAD performance. In the optimization of the $\mathrm{pH}$ value, we added 1-2 $\mu \mathrm{L} \mathrm{K}_{2} \mathrm{CO}_{3}(0.5 \mathrm{M})$ and observed Au@PtNP coagulation. When we added 3-10 $\mu \mathrm{L} \mathrm{K} \mathrm{C}_{2} \mathrm{CO}_{3}$ $(0.5 \mathrm{M}), \mathrm{UV}$-vis results suggested a similar peak at approximately $523 \mathrm{~nm}$ in Figure $4 \mathrm{~A}$. The highest optical destiny (OD) produced with an additional $3 \mu \mathrm{L}$ of $\mathrm{K}_{2} \mathrm{CO}_{3}(0.5 \mathrm{M})$ was chosen as the optimized value with $\mathrm{pH}$ at 7.3. The optimized results of the blocking buffer are shown in Figure 4B. Compared with OVA-PBS and Milk-PBS, the use of casein-PBS (w/v) enabled better sensitivity. We further investigated the use of IgG. During the synthesis of Au@PtNPs-IgG, if the IgG final concentration was less than $12 \mu \mathrm{g} / \mathrm{mL}$, then coagulation was produced: we observed a homogeneous solution for the IgG final concentration above $12 \mu \mathrm{g} / \mathrm{mL}$. According to the UV-vis results (Figure 4C), we chose the IgG final concentration of $16 \mu \mathrm{g} / \mathrm{mL}$, which corresponded with the highest OD value. We further conducted POCAD to evaluate the sensitivity with IgG final concentrations ranging from $12-20 \mu \mathrm{g} / \mathrm{mL}$, resulting in the same final $\mathrm{IgG}$ concentration of $16 \mu \mathrm{g} / \mathrm{mL}$ with the best sensitivity (Figure 4D).

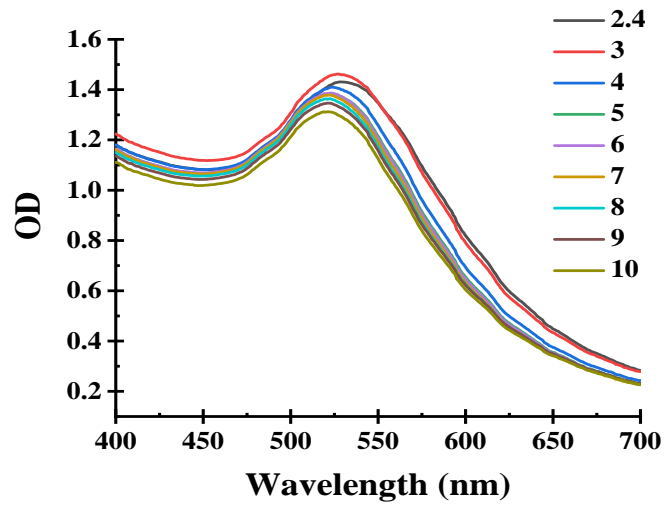

(A)

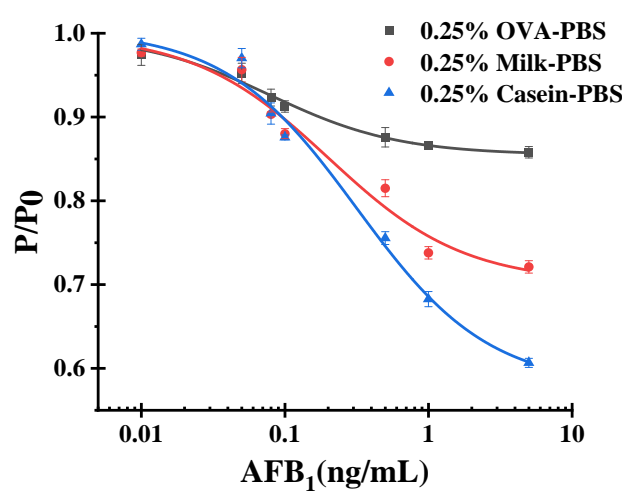

(B)

Figure 4. Cont. 


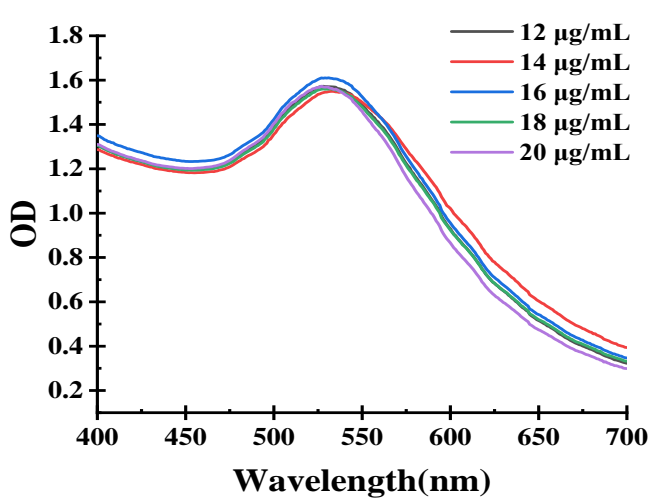

(C)

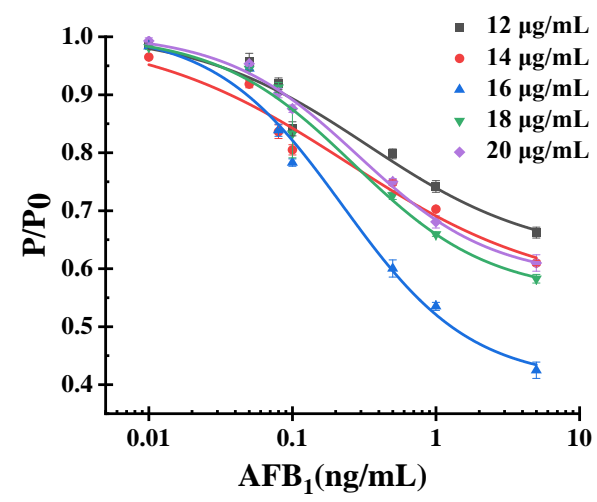

(D)

Figure 4. Optimization of Au@PtNPs and Au@PtNPs-IgG: (A) UV-visible spectroscopy scanning of $\mathrm{Au} @$ PtNPs with 1-10 $\mu \mathrm{L} \mathrm{K}_{2} \mathrm{CO}_{3}(0.5 \mathrm{M})$ to adjust the $\mathrm{pH}$ value of the reaction system; (B) different blocking buffers for Au@PtNPs; (C) UV-visible spectroscopy scanning of Au@PtNPs-IgG among different concentrations $(12,14,16,18,20 \mu \mathrm{g} / \mathrm{mL}$ ) of goat anti-mouse antibody; (D) different final concentrations $(12,14,16,18,20 \mu \mathrm{g} / \mathrm{mL})$ of goat anti-mouse antibody in the reaction system.

\subsection{Characterization of $A u @ P t N P s-I g G$}

As shown in Figure 2B, we observed the obvious redshift from 517 to 531 nm after Au@PtNPs were conjugated with IgG along with the slight enhancement of the optical intensity. The reason for the redshift was the growing diameter of Au@PtNPs before and after conjugation with IgG. The colors of Au@PtNPs and Au@PtNPs-IgG were darker compared with the red color of AuNPs. From the HRTEM analysis, the diameter of Au@PtNPs increased slightly after conjugation with IgG, indicating the successful conjugation of IgG on Au@PtNPs (Figure 3B,D).

The elemental mapping results (Figure 3E-J) proved the positive results of Au@PtNPs-IgG synthesis. As demonstrated through Figure $3 \mathrm{E}, \mathrm{F}$ and $\mathrm{G}$, the elemental mapping results indicated that the structure of Au@Pt was successfully formed. Comparing Figure 3J with Figure 3E-I, we found that $\mathrm{N}$ and $\mathrm{O}$ elements were mainly distributed around $\mathrm{Au} @ P t N P s$, which indicated that the antibody was successfully connected to Au@PtNPs (the main elements of antibodies are C, H, O, and N. In this paper, we select $\mathrm{N}$ and $\mathrm{O}$ as value standards because the base of the carrier was a membrane of $\mathrm{C}$ ).

According to energy dispersive spectroscopy (EDS) pattern results (Figure 5), we observed the apparent growing intensity of $\mathrm{C}, \mathrm{N}$, and $\mathrm{O}$, suggesting the conjugation of IgG with Au@PtNPs. Specifically, other than Au@PtNPs, N only appeared in Au@PtNPs-IgG. The intensity values of $\mathrm{C}$ and O increased $78.9 \%$ and $509 \%$, respectively.

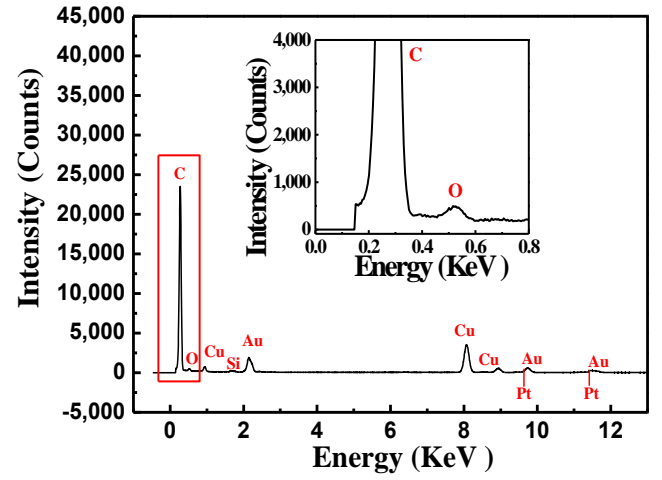

(A)

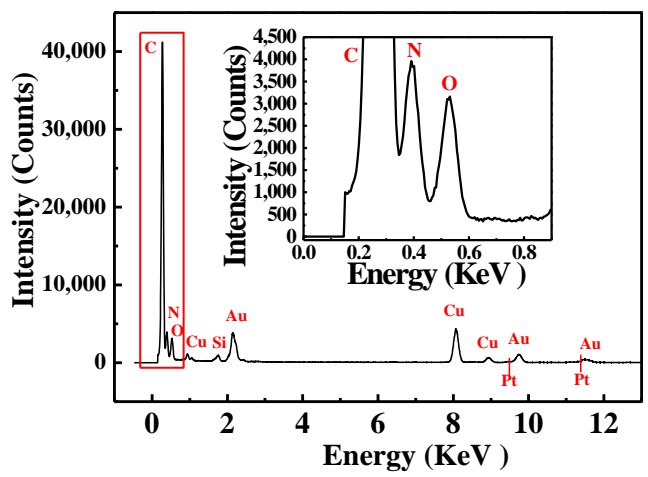

(B)

Figure 5. Energy dispersive spectroscopy patterns of Au@PtNPs (A) and Au@PtNPs-IgG (B), illustrations are the magnification of the corresponding $C, N, O$ element. 


\subsection{Optimization of POCAD}

\subsubsection{Blocking Solution for Immunoassay}

The blocking buffer for the immunoassay would influence the immunoassay results. Three kinds of blocking buffer were studied: 1.5\% OVA-PBST (w/v), 0.25\% casein-PBST (w/v), and $2.5 \%$ nonfat milk-PBST $(\mathrm{w} / \mathrm{v})$. As shown in Figure 6A, better sensitivity was found when we employed 2.5\% milk-PBST.

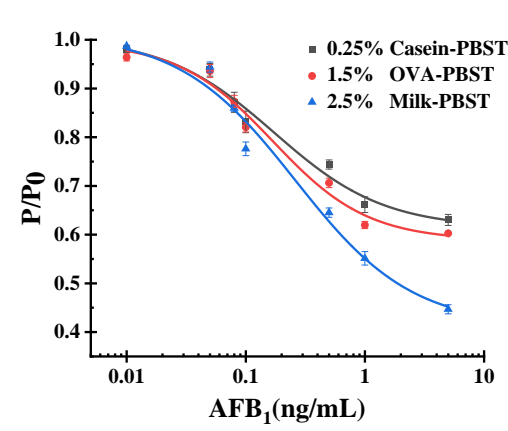

(A)

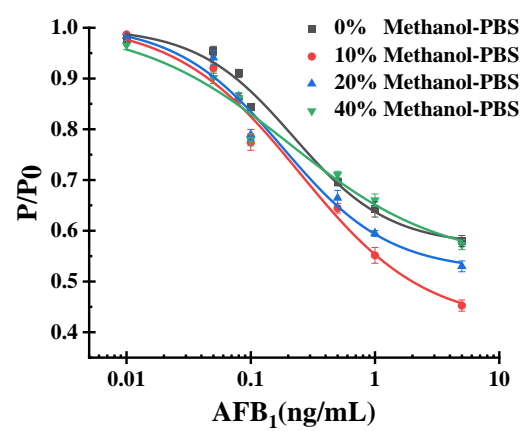

(B)

Figure 6. Optimization of the characteristics which influence the pressure results of the reaction system: (A) influence of the different blocking buffers for pressure reaction; (B) influence of the different concentrations of methanol on the immune reaction.

\subsubsection{Methanol Concentration for Immunoassay}

The concentration of methanol has a significant effect on the combination of antibody and antigen. The sensitivity of this system decreases with increasing amounts of methanol. In this research, we have compared a series of concentrations of methanol including $0 \%, 10 \%, 20 \%$, and $40 \%$. We determined that $10 \%$ methanol was better than the other concentrations due to its superior sensitivity, shown in Figure $6 \mathrm{~B}$. After the optimization of these items above, we could obtain an excellent parameter combination.

\subsection{Standard Curve and LOD}

By using the aflatoxins standard solution, we obtained the standard curve (Figure 7) under the optimal situation. Through nonlinear fitting, we obtained Formula (1) to calculate the content of aflatoxins in detected samples. By calculating, we obtained the half-maximal inhibitory concentration $\left(\mathrm{IC}_{50}\right)$ of POCAD of $0.24 \mathrm{ng} / \mathrm{mL}$ with the LOD of $0.03 \mathrm{ng} / \mathrm{mL}$. The linear range of this approach was $0.09-16.0 \mathrm{ng} / \mathrm{mL}$.

$$
y=0.45+0.55 /\left(1+(x / 0.24)^{1.12}\right), R^{2}=0.997
$$

The sensitivity comparison between POCAD and the previous study are reported in Table 1. According to the date reported in the previous works, the sensitivity of POCAD was at least three times lower than the other methods.

Table 1. Sensitivity comparison between POCAD and previous reports.

\begin{tabular}{cccc}
\hline Assay Methods & Assay Target & LOD (ng/mL) & Reference \\
\hline Europium nanospheres-based time-resolved fluorescence & $\mathrm{AFTs}^{1}$ & 0.16 & {$[24]$} \\
immunoassay & $\mathrm{AFB}_{1}$ & 2.5 & {$[25]$} \\
Fluorescent microspheres-based test strip & $\mathrm{AFB}_{1}$ & 0.3 & {$[26]$} \\
Aptamer based test strip & $\mathrm{AFB}_{1}$ & 0.1 & {$[27]$} \\
POCAD & $\mathrm{AFTs}$ & 0.03 & This work \\
\hline
\end{tabular}

${ }^{1}$ AFTs is the abbreviation of total aflatoxins. 


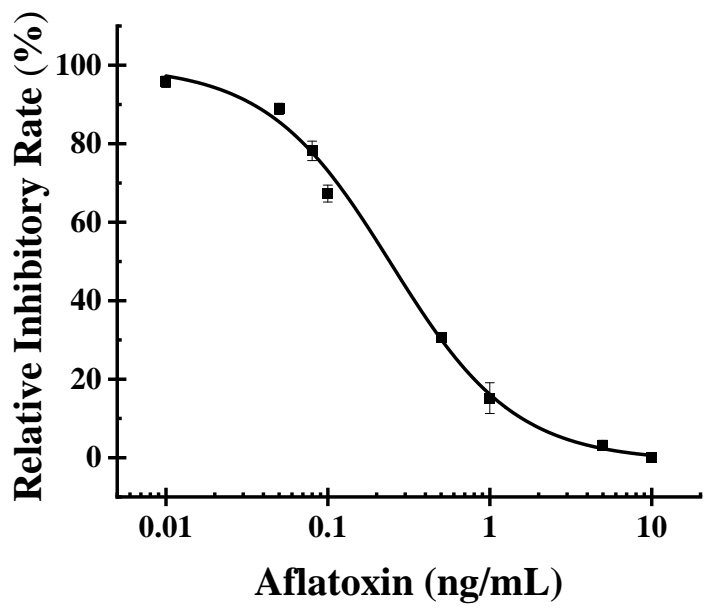

Figure 7. Standard curve for aflatoxin quantitation. The pressure data was obtained by using the aflatoxins standard solution ranging from $0-10 \mathrm{ng} / \mathrm{mL}$. The relative inhibitory rate (RIR) was calculated by the formula $\left(R I R=\left(1-\left(P-P_{m}\right) /\left(P_{0}-P_{m}\right)\right) \times 100 \%\right)$, where $P_{0}$ and $P_{m}$ were the pressure values corresponding to aflatoxin concentration of 0 and $10 \mathrm{ng} / \mathrm{mL}$, respectively, and $P$ represents the pressure values of other aflatoxin concentrations. The standard curve fit through the formula $(y=0.45+0.55 /(1$ $\left.\left.+(\mathrm{x} / 0.24)^{1.12}\right), \mathrm{R}^{2}=0.997\right)$.

\subsection{Recovery}

To validate the accuracy of POCAD, we employed this method to detect negative samples (peanut) with additional aflatoxins. From this detection, we could obtain the average recovery by the pressure readout method. The aflatoxins in detected samples were quantitated through the standard curve. As shown in Table 2, including inner-assay and inter-assay results, the strong average recovery of this method $(83.1 \%-112.0 \%)$ indicated that this method was satisfactory for spiked sample detection.

Table 2. Results of recovery analysis by POCAD.

\begin{tabular}{ccccc}
\hline & $\begin{array}{c}\text { Spike Level } \\
(\boldsymbol{\mu} \mathbf{g} / \mathbf{k g})\end{array}$ & Mean \pm SD & $\begin{array}{c}\text { Average Recovery } \\
(\mathbf{\%})\end{array}$ & $\begin{array}{c}\text { Relative Standard } \\
\text { Deviation } \\
(\text { RSD } \%)\end{array}$ \\
\hline Within & 5 & $4.25 \pm 0.25^{\mathrm{c}}$ & 85.0 & 5.8 \\
assay $(n=3)^{\mathrm{a}}$ & 15 & $16.79 \pm 0.72$ & 112.0 & 4.3 \\
Between assay $_{(n=5)^{\mathrm{b}}}$ & 5 & $19.33 \pm 0.52$ & 96.7 & 2.7 \\
& 15 & $4.15 \pm 0.16$ & 83.1 & 3.8 \\
& 20 & $14.87 \pm 0.34$ & 99.1 & 2.3 \\
\hline
\end{tabular}

a The experiments were carried out in three replicates on the same day; ${ }^{b}$ the assays were carried out on five different days. ${ }^{c}$ The data are average values and standard deviation (SD).

\subsection{Within Assay and between Assay}

By analyzing the inner-assay and inter-assay in Table 2, we could calculate that the relative standard distribution (RSD) values separately ranged from $2.7 \%$ to $5.8 \%$ and $2.3 \%$ to $6.4 \%$. These results indicated that POCAD was stable and suitable for development as a rapid aflatoxin detection method.

\subsection{Validation via HPLC Using Peanut and Corn Samples}

To estimate the accuracy of POCAD, we employed the six agricultural samples (peanut and corn) to perform this method and HPLC separately. The sample preparation and method performance were conducted according to the protocol described above. By comparing the results of POCAD and 
HPLC separately (shown in Table 3), we found proper agreement between the two analytical methods, as presented in the results $\left(y=0.22 x+0.99, R^{2}=99.2 \%\right)$.

Table 3. Comparison of real samples detection by POCAD and HPLC.

\begin{tabular}{ccc}
\hline Samples & $\begin{array}{c}\text { This Work } \\
(\mu \mathrm{g} / \mathbf{k g} \boldsymbol{n}=3)^{\mathrm{a}}\end{array}$ & $\begin{array}{c}\text { HPLC } \\
(\mu \mathrm{g} / \mathbf{k g} \boldsymbol{n}=3)\end{array}$ \\
\hline 1 & $4.86 \pm 0.34^{\mathrm{b}}$ & $4.87 \pm 0.08$ \\
2 & $15.10 \pm 0.50$ & $15.04 \pm 0.40$ \\
3 & $22.51 \pm 0.95$ & $21.64 \pm 0.25$ \\
4 & $4.22 \pm 0.26$ & $4.13 \pm 0.10$ \\
5 & $13.38 \pm 0.52$ & $14.01 \pm 0.17$ \\
6 & $18.98 \pm 0.95$ & $19.62 \pm 0.2$ \\
\hline
\end{tabular}

${ }^{a}$ The experiments were carried out in three replicates on the same day. ${ }^{b}$ The data are average values and SD.

\section{Conclusions}

The point-of-care detection of hazardous small molecules is important in agro-food safety. Using aflatoxin as an example, we developed a sensitive point-of-care detection method for small molecules based on a portable handheld barometer. The Au@PtNPs were synthesized and then conjugated with IgG as a signal amplifier. Based on the excellent catalytic efficiency of Au@PtNPs, the immuno-reaction results indicated effective $\mathrm{O}_{2}$ generation, which produced increased pressure signals in a sealed system. By using a handheld gas meter, we obtained the aflatoxin concentration rapidly and precisely. After optimization, we recorded the LOD of $0.03 \mathrm{ng} / \mathrm{mL}$, and a linear range of 0.09 to $16.0 \mathrm{ng} / \mathrm{mL}$ along with average recovery of $83.1 \%-112.0 \%$ and slight cross-reactivity. The inner-assay and inter-assay results demonstrated satisfactory RSD $(<6.4 \%)$. Accuracy was further validated by a typical HPLC method. This proposal suggests potential application in POC detection in food safety.

\section{Materials and Methods}

\subsection{Chemicals and Instruments}

Aflatoxins mix standard solution, 4-(2-hydroxyethyl)-1-piperazineethanesulfonic acid (HEPES), $\mathrm{HAuCl}_{4} \cdot 3 \mathrm{H}_{2} \mathrm{O}$, and $\mathrm{H}_{2} \mathrm{PtCl}_{6} \cdot \mathrm{xH} 2 \mathrm{O}, 30 \% \mathrm{H}_{2} \mathrm{O}_{2}$ were obtained from Sigma-Aldrich, Inc. (Shanghai, China). Trisodium citrate, ascorbic acid, Tween 20, and sucrose were obtained from Sinopharm Chemical Reagent Co., Ltd. (Beijing, China). Phosphate-buffered saline (PBS, $0.01 \mathrm{M}, \mathrm{pH} 7.4$ ) was prepared by adding $2.9 \mathrm{~g}$ of $\mathrm{Na}_{2} \mathrm{HPO}_{4} \cdot 12 \mathrm{H}_{2} \mathrm{O}, 0.2 \mathrm{~g}$ of $\mathrm{KCl}, 0.2 \mathrm{~g}$ of $\mathrm{KH}_{2} \mathrm{PO}_{4}$, and $8 \mathrm{~g}$ of $\mathrm{NaCl}$ into $1 \mathrm{~L}$ of deionized water. Carbonate buffer $\left(0.05 \mathrm{M}, \mathrm{pH}\right.$ 9.6) was prepared by adding $2.93 \mathrm{~g}$ of $\mathrm{NaHCO}_{3}$ and $1.59 \mathrm{~g}$ of $\mathrm{Na}_{2} \mathrm{CO}_{3}$ into $1 \mathrm{~L}$ of deionized water. Water was purified by a MilliQ system (Millipore, Danvers, MA, USA). All reagents applied were of analytical grade unless otherwise specified. All of the glassware was cleaned with aqua regia $\left(\mathrm{HNO}_{3}: \mathrm{HCl}=1: 3(\mathrm{v} / \mathrm{v})\right)$ before use. The monoclonal antibody $(\mathrm{mAb}) 1 \mathrm{C} 11$ for aflatoxins was produced by our own laboratory [28]. Goat anti-mouse antibody was obtained from GE Healthcare Co., Ltd. (Piscataway, NJ, USA).

The ultraviolet spectrum was acquired by a SpectraMax M2e microplate reader (Molecular Devices Corp., Sunnyvale, CA, USA). X-ray diffraction (XRD) patterns were obtained by a Bruker D8 Advance instrument (Bruker AXS Co. Ltd., Karlsruhe, Germany) with a $\mathrm{Cu}$ Ka radiation source $(\lambda=0.15406 \mathrm{~nm})$. High-resolution transmission electron microscopy (HRTEM), elemental mapping and energy dispersive spectroscopy (EDS) were performed using a JEM-2100F TEM facility (Jeol Ltd., Tokyo, Japan).

\subsection{Synthesis and Characterization of $A u @ P t N P s-I g G$}

First, AuNPs were synthesized by a reduction method [29]. Four milliliters of $1 \%$ trisodium citrate was added into $200 \mathrm{~mL}$ of $0.01 \%(\mathrm{w} / \mathrm{v}) \mathrm{HAuCl}_{4}$ under reflux. The reaction was refluxed for 
$20 \mathrm{~min}$ before cooling to room temperature naturally, and the AuNPs were stored at $4{ }^{\circ} \mathrm{C}$ before use. Second, the Au@PtNPs were synthesized via seed-mediated growth. Ten milliliters of AuNPs solution was mixed with $200 \mu \mathrm{L}$ of $3.86 \mathrm{mM} \mathrm{H}_{2} \mathrm{PtCl}_{4}$ at $80{ }^{\circ} \mathrm{C}$ with gentle stirring for $5 \mathrm{~min}$. Then, $400 \mu \mathrm{L}$ of $10 \mathrm{mM}$ ascorbic acid was added dropwise and kept at $80^{\circ} \mathrm{C}$ for $30 \mathrm{~min}$. After cooling naturally, the Au@PtNPs were stored at $4{ }^{\circ} \mathrm{C}$ until further use.

Before the synthesis of Au@PtNPs-IgG, the pH value of Au@PtNPs was optimized. After 1-10 $\mu \mathrm{L}$ $\mathrm{K}_{2} \mathrm{CO}_{3}(0.5 \mathrm{M})$ was added into $1 \mathrm{~mL}$ of $\mathrm{Au} @ P t N P$ s solution to adjust the $\mathrm{pH}$ value, the optimal $\mathrm{pH}$ of the reaction solution was confirmed through UV-vis. After that step, a saturated concentration of anti-mouse antibody was added into Au@PtNPs solution and incubated for $30 \mathrm{~min}$ at $37^{\circ} \mathrm{C}$. Then, the equal volume of blocking buffer (0.25\% OVA-PBS, $0.25 \%$ milk-PBS, $0.25 \%$ casein-PBS, w/v) was added and incubated at $37^{\circ} \mathrm{C}$ for $1 \mathrm{~h}$. After centrifugation ( $9000 \mathrm{~g}$ at $4{ }^{\circ} \mathrm{C}$ for $\left.10 \mathrm{~min}\right)$, the precipitate was resuspended with the stock solution (10 mM HEPES, $10 \mathrm{mM}$ citric acid, 0.1\% Tween 20, 5\% sucrose, $\mathrm{pH}=7$ ). The Au@PtNPs-IgG solution was stored at $4{ }^{\circ} \mathrm{C}$ before use.

We synthesized the Au@PtNPs-IgG solution by changing the amount of the IgG (final concentration: 10-20 $\mu \mathrm{g} / \mathrm{mL})$. The optimal amount of IgG was confirmed through UV-vis spectrum scanning from 400-700 nm.

UV-visual spectroscopy was employed to characterize AuNPs, Au@PtNPs, and Au@PtNPs-IgG. The crystalline structure of Au@PtNPs was identified by X-ray diffraction with angles from $30^{\circ}$ to $90^{\circ}$, as well as selected area electron diffraction (SAED). The pattern of EDS exhibited all elements of Au@PtNPs. The morphological characteristics of AuNPs, Au@PtNPs, and Au@PtNPs-IgG were analyzed by high-resolution transmission electron microscopy (HRTEM). The elemental mapping of the pattern of the energy dispersive spectrometer exhibited the elements of Au@PtNPs-IgG. The elemental mapping showed a variety of elements and positions of Au@PtNPs-IgG.

\subsection{Fabrication of POCAD}

The POCAD comprised a microwell plate and a handheld barometer. A rubber strip was used to seal the microwell plate as a cover. After POCAD was conducted, a portable handheld barometer was used to measure the gas pressure in the sealed microwell.

\subsection{Procedure of POCAD}

One hundred microliters of $0.05 \mathrm{M}$ carbonate buffer containing $\mathrm{AFB}_{1}-\mathrm{BSA}(0.5 \mu \mathrm{g} / \mathrm{mL})$ in a microwell plate was incubated at $4{ }^{\circ} \mathrm{C}$ for $12 \mathrm{~h}$. After washing three times with $0.05 \%$ PBST $(0.01 \mathrm{M}$ PBS with $0.05 \%$ Tween 20), the well was blocked with a blocking buffer at $37^{\circ} \mathrm{C}$ for $1 \mathrm{~h}$. The microwell was washed three times with $0.05 \%$ PBST. In a microwell, $100 \mu \mathrm{L}$ of the mixture of aflatoxin standard solution (final concentration ranged from $0-20 \mathrm{ng} / \mathrm{mL}$ in $5 \% \mathrm{MeOH}$ ) and monoclonal antibody (final concentration: $0.5 \mu \mathrm{g} / \mathrm{mL}$ ) was incubated at $37^{\circ} \mathrm{C}$ for $1 \mathrm{~h}$ and then washed three times with 0.05\% PBST. One hundred microliters of Au@PtNPs-IgG solution was added into these wells and incubated at $37^{\circ} \mathrm{C}$ for another $1 \mathrm{~h}$. The microwell was washed six times with $0.05 \%$ PBST to ensure that superfluous Au@PtNPs-IgG was removed. Then, $100 \mu \mathrm{L}$ of $\mathrm{H}_{2} \mathrm{O}_{2}$ was added. The catalysis of Au@PtNPs-IgG on $\mathrm{H}_{2} \mathrm{O}_{2}$ was conducted for $15 \mathrm{~min}$. The pressure values of the microwell were obtained by a handheld barometer.

\subsection{Optimization of POCAD}

We analyzed 1.5\% OVA-PBST (w/v), 0.25\% casein-PBST (w/v), and 2.5\% nonfat milk-PBST (w/v) as blocking buffers. The concentration of methanol was also optimized with final concentrations of $0 \%, 5 \%, 10 \%$, and 20\%. The best blocking buffer and the optimal final methanol concentration were recorded according to the sensitivity of POCAD. 


\subsection{Evaluation of POCAD}

\subsubsection{LOD and Linear Range}

The POCAD standard curve was determined via a series of aflatoxin standard solutions (0-10 ng/mL). The standard curve was established by fitting the inhibitory concentration value versus the concentration of aflatoxins using four parameter logistic regression. The LOD, sensitivity, and linear range were calculated according to previous research [30].

\subsubsection{Recovery, Inner-Assay Precision and Inter-Assay Precision}

To evaluate the recovery, inner-assay precision, and inter-assay precision of POCAD, we spiked aflatoxins (final concentration: $5-20 \mathrm{ng} / \mathrm{mL}$ ) in blank peanut and corn samples. Then, the samples were ground into homogenized powders and stored overnight at room temperature. Under optimization, we used the POCAD to record the recovery.

The inner-assay experiment was conducted by detecting spiked samples (final concentration: 5-20 ng/mL) of aflatoxins within one day, while the inter-assay experiment was conducted by using the spiked samples (final concentration: $5-10 \mathrm{ng} / \mathrm{mL}$ ) on day 1 and day 5.

\subsection{Validation via Immune Affinity Column-HPLC}

The POCAD was validated with the immune affinity column (IAC)-HPLC-FLD (fluorescence detector) method. We used homemade IAC with $10 \mathrm{~mL}$ dilution, as in our previous protocol [31]. In HPLC, we employed a $C_{18}$ column (particle size $3 \mu \mathrm{m}, 150 \mathrm{~mm} \times 4.6 \mathrm{~mm}$ ). The excitation wavelength of the fluorescence detector was set as $360 \mathrm{~nm}$, while the emission wavelength was set as $440 \mathrm{~nm}$. The injection volume of samples was fixed as $10 \mu \mathrm{L}$, while the column temperature was confirmed as $30{ }^{\circ} \mathrm{C}$ The mobile phase was $45 \%$ methanol-water solution at the flow rate of $1 \mathrm{~mL} / \mathrm{min}$.

\subsection{Sample Pretreatment}

Peanut and corn samples, purchased from a local supermarket, were used to evaluate the performance of the POCAD method. After grinding, the homogenized peanut and corn powder samples ( $5 \mathrm{~g}$ ) were added to $20 \mathrm{~mL}$ of $80 \%$ (v/v) methanol solution and homogenized with a high-speed vortex mixer (Vortex-Genie2, SI, New York, NY, USA) for $3 \mathrm{~min}$. After filtration with a glass fiber filter, $10 \mathrm{~mL}$ of the filtrate was diluted with four volumes of deionized water. The dilution was stored at $4{ }^{\circ} \mathrm{C}$ until further use.

Author Contributions: Conceptualization, Z.Z. and P.L.; data curation, W.Z. and W.W.; funding acquisition, Z.Z. and P.L.; methodology, Z.Z. and P.L.; project administration, Z.Z. and P.L.; resources, Y.B.; software, W.W. and C.C.; validation, W.Z. and W.W.; visualization, W.Z. and C.C.; writing-original draft, W.Z.; writing-review \& editing, X.H., H.L. and Z.Z. All authors have read and agreed to the published version of the manuscript.

Funding: This work was supported by the National Key R\&D Program of China (2016YFF0201901), the Agricultural Science and Technology Innovation Program of CAAS (CAAS-XTCX2019024) and the National Natural Science Foundation of China (31801665).

Conflicts of Interest: The authors declare no competing financial interest.

\section{References}

1. Lee, H.J.; Ryu, D. Worldwide occurrence of mycotoxins in cereals and cereal-derived food products: Public health perspectives of their co-occurrence. J. Agric. Food Chem. 2017, 65, 7034-7051. [CrossRef] [PubMed]

2. Nesbitt, B.F.; O'Kelly, J.; Sargeant, K.; Sheridan, A. Aspergillus flavus and turkey X disease. Toxic metabolites of aspergillus flavus. Nature 1962, 195, 1062-1063. [CrossRef] [PubMed]

3. Kensler, T.W.; Roebuck, B.D.; Wogan, G.N.; Groopman, J.D. Aflatoxin: A 50-year odyssey of mechanistic and translational toxicology. Toxicol. Sci. 2011, 120, S28-S48. [CrossRef] [PubMed] 
4. Henry, S.H.; Bosch, F.X.; Troxell, T.C.; Bolger, P.M. Public health-Reducing liver cancer-Global control of aflatoxin. Science 1999, 286, 2453-2454. [CrossRef] [PubMed]

5. Liu, Y.; Wu, F. Global burden of aflatoxin-induced hepatocellular carcinoma: A risk assessment. Environ. Health Perspect. 2010, 118, 818-824. [CrossRef] [PubMed]

6. Shephard, G.S. Aflatoxin analysis at the beginning of the twenty-first century. Anal. Bioanal. Chem. 2009, 395, 1215-1224. [CrossRef]

7. Xu, L.; Zhang, H.; Yan, X.; Peng, H.; Wang, Z.; Zhang, Q.; Li, P.; Zhang, Z.; Le, X.C. Binding-induced DNA dissociation assay for small molecules: Sensing aflatoxin B1. ACS Sens. 2018, 3, 2590-2596. [CrossRef]

8. Yu, L.; Ma, F.; Ding, X.X.; Wang, H.L.; Li, P.W. Silica/graphene oxide nanocomposites: Potential adsorbents for solid phase extraction of trace aflatoxins in cereal crops coupled with high performance liquid chromatography. Food Chem. 2018, 245, 1018-1024. [CrossRef]

9. McCullum, C.; Tchounwou, P.; Ding, L.-S.; Liao, X.; Liu, Y.-M. Extraction of aflatoxins from liquid foodstuff samples with polydopamine-coated superparamagnetic nanoparticles for Hplc-Ms/Ms analysis. J. Agric. Food Chem. 2014, 62, 4261-4267. [CrossRef]

10. Liu, B.-H.; Chu, K.-C.; Yu, F.-Y. Novel monoclonal antibody-based sensitive enzyme-linked immunosorbent assay and rapid immunochromatographic strip for detecting aflatoxin M1 in milk. Food Control 2016, 66, 1-7. [CrossRef]

11. Li, Y.; Xuan, J.; Song, Y.J.; Qi, W.J.; He, B.S.; Wang, P.; Qin, L.D. Nanoporous glass integrated in volumetric bar-chart chip for point-of-care diagnostics of non-small cell lung cancer. ACS Nano 2016, 10, 1640-1647. [CrossRef] [PubMed]

12. Ma, Y.L.; Mao, Y.; Huang, D.; He, Z.; Yan, J.M.; Tian, T.; Shi, Y.Z.; Song, Y.L.; Li, X.R.; Zhu, Z.; et al. Portable visual quantitative detection of aflatoxin B-1 using a target-responsive hydrogel and a distance-readout microfluidic chip. Lab Chip 2016, 16, 3097-3104. [CrossRef] [PubMed]

13. Liu, D.; Jia, S.S.; Zhang, H.M.; Ma, Y.L.; Guan, Z.C.; Li, J.X.; Zhu, Z.; Ji, T.H.; Yang, C.J. Integrating target-responsive hydrogel with pressuremeter readout enables simple, sensitive, user-friendly, quantitative point-of-care testing. ACS Appl. Mater. Interfaces 2017, 9, 22252-22258. [CrossRef] [PubMed]

14. Liu, D.; Tian, T.; Chen, X.; Lei, Z.; Song, Y.; Shi, Y.; Ji, T.; Zhu, Z.; Yang, L.; Yang, C. Gas-generating reactions for point-of-care testing. Analyst 2018, 143, 1294-1304. [CrossRef] [PubMed]

15. Engelbrekt, C.; Seselj, N.; Poreddy, R.; Riisager, A.; Ulstrup, J.; Zhang, J. Atomically thin Pt shells on Au nanoparticle cores: Facile synthesis and efficient synergetic catalysis. J. Mater. Chem. A 2016, 4, 3278-3286. [CrossRef]

16. Huang, D.; Lin, B.; Song, Y.; Guan, Z.; Cheng, J.; Zhu, Z.; Yang, C. Staining traditional colloidal gold test strips with Pt nanoshell enables quantitative point-of-care testing with simple and portable pressure meter readout. ACS Appl. Mater. Interfaces 2019, 11, 1800-1806. [CrossRef] [PubMed]

17. Lou, Y.B.; Maye, M.M.; Han, L.; Luo, J.; Zhong, C.J. Gold-platinum alloy nanoparticle assembly as catalyst for methanol electrooxidation. Chem. Commun. 2001, 5, 473-474. [CrossRef]

18. Fu, Q.; Wu, Z.; Li, J.; Wu, Z.; Zhong, H.; Yang, Q.; Liu, Q.; Liu, Z.; Sheng, L.; Xu, M.; et al. Quantitative assessment of disease markers using the naked eye: Point-of-care testing with gas generation-based biosensor immunochromatographic strips. J. Nanobiotechnol. 2019, 17, 67. [CrossRef]

19. Zhu, Z.; Guan, Z.; Jia, S.; Lei, Z.; Lin, S.; Zhang, H.; Ma, Y.; Tian, Z.-Q.; Yang, C.J. Au@Pt nanoparticle encapsulated target-responsive hydrogel with volumetric bar-chart chip readout for quantitative point-of-care testing. Angew. Chem. Int. Ed. 2014, 53, 12503-12507.

20. Huang, Y.; Ma, Y.; Chen, Y.; Wu, X.; Fang, L.; Zhu, Z.; Yang, C.J. Target-responsive dnazyme cross-linked hydrogel for visual quantitative detection of lead. Anal. Chem. 2014, 86, 11434-11439. [CrossRef]

21. Yang, Z.Y.; Liu, X.L.; Zheng, X.H.; Zheng, J.B. Synthesis of Au@Pt nanoflowers supported on graphene oxide for enhanced electrochemical sensing of dopamine. J. Electroanal. Chem. 2018, 817, 48-54. [CrossRef]

22. Yang, Z.; Zheng, X.; Zheng, J. Facile synthesis of three-dimensional porous Au@Pt core-shell nanoflowers supported on graphene oxide for highly sensitive and selective detection of hydrazine. Chem. Eng. J. 2017, 327, 431-440. [CrossRef]

23. Peng, C.F.; Pan, N.; Qian, Z.J.; Wei, X.L.; Shao, G. Colorimetric detection of thiocyanate based on inhibiting the catalytic activity of cystine-capped core-shell Au@Pt nanocatalysts. Talanta 2017, 175, 114-120. [CrossRef] [PubMed] 
24. Wang, D.; Zhang, Z.; Li, P.; Zhang, Q.; Ding, X.; Zhang, W. Europium nanospheres-based time-resolved fluorescence for rapid and ultrasensitive determination of total aflatoxin in feed. J. Agric. Food Chem. 2015, 63, 10313-10318. [CrossRef]

25. Liu, D.; Huang, Y.; Chen, M.; Wang, S.; Liu, K.; Lai, W. Rapid detection method for aflatoxin B-1 in Soybean sauce based on fluorescent microspheres probe. Food Control 2015, 50, 659-662. [CrossRef]

26. Yu, L.; Li, P.; Ding, X.; Zhang, Q. Graphene oxide and carboxylated graphene oxide: Viable two-dimensional nanolabels for lateral flow immunoassays. Talanta 2017, 165, 167-175. [CrossRef]

27. Zhu, C.; Zhang, G.; Huang, Y.; Yang, S.; Ren, S.; Gao, Z.; Chen, A. Dual-competitive lateral flow aptasensor for detection of aflatoxin B-1 in food and feedstuffs. J. Hazard. Mater. 2018, 344, 249-257. [CrossRef]

28. Zhang, D.H.; Li, P.W.; Zhang, Q.; Zhang, W.; Huang, Y.L.; Ding, X.X.; Jiang, J. Production of ultrasensitive generic monoclonal antibodies against major aflatoxins using a modified two-step screening procedure. Anal. Chim. Acta 2009, 636, 63-69. [CrossRef] [PubMed]

29. Li, X.; Li, P.; Zhang, Q.; Li, R.; Zhang, W.; Zhang, Z.; Ding, X.; Tang, X. Multi-component immunochromatographic assay for simultaneous detection of aflatoxin B-1, ochratoxin A and zearalenone in agro-food. Biosens. Bioelectron. 2013, 49, 426-432. [CrossRef]

30. Liu, Z.J.; Zhang, B.; Sun, J.F.; Yi, Y.H.; Li, M.; Du, D.L.; Zhu, F.; Luan, J.W. Highly efficient detection of salbutamol in environmental water samples by an enzyme immunoassay. Sci. Total Environ. 2018, 613, 861-865. [CrossRef]

31. Hu, X.F.; Hu, R.; Zhang, Z.W.; Li, P.W.; Zhang, Q.; Wang, M. Development of a multiple immunoaffinity column for simultaneous determination of multiple mycotoxins in feeds using Uplc-Ms/Ms. Anal. Bioanal. Chem. 2016, 408, 6027-6036. [CrossRef] [PubMed]

(C) 2020 by the authors. Licensee MDPI, Basel, Switzerland. This article is an open access article distributed under the terms and conditions of the Creative Commons Attribution (CC BY) license (http://creativecommons.org/licenses/by/4.0/). 